Wahana Didaktika Vol. 18 No.3 September 2020 : 338-346

\title{
PENGARUH MODEL PEMBELAJARAN OUTBOUND TERHADAP KEMAMPUAN MENULIS PUISI SISWA MTS NEGERI 1 EMPAT LAWANG
}

\author{
Oleh : Muhammad Syaifudin, Achmad Wahidy, Barkudin \\ Email : muhammadsyaifudin745@gmail.com, achmadwahidy@gmail.com
}

\author{
(Universitas PGRI Palembang)
}

\begin{abstract}
Abstrak
Permasalahan dalam penelitian ini mengenai apakah ada pengaruh model pembelajaran Outbound terhadap kemampuan menulis puisi. Tujuan dalam penelitian ini untuk mengetahui apakah terdapat pengaruh metode pembelajaran Outbound terhadap kemampuan menulis puisi. Penelitian ini menggunakan metode Design Only Posttest Control. Variabel bebas dalam penelitian ini model pembelajaran Outbound dan variabel terikat yaitu menulis puisi. Populasi yang digunakan dalam penelitian ini yaitu 6 kelas, sampel penelitian siswa kelas VIII.6 kelas eksperimen dan kelas VIII.3 kelas kontrol. Pengumpulan menggunakan teknik tes, teknik analisis data menggunakan uji t. Berdasarkan kriteria pengujian hipotesis bahwa Ho diterima jika $t_{\text {hitung }}<t_{\text {tabel }}$ dan Ha diterima jika $t_{\text {hitung }}>t_{\text {tabel }}$ oleh karena itu $t_{\text {hitung }}$ dengan nilai 11,71 lebih besar dibandingkan $t_{\text {tabel }}$ dengan nilai 1,66 sehingga ada pengaruh metode Outbound dalam menulis puisi siswa kelas VIII MTS N 1 Empat Lawang.
\end{abstract}

Kata Kunci : Model Pembelajaran Outbound, Menulis Puisi

\section{THE INFLUENCE OF OUTBOUND LEARNING METODE TO WRITING ABILITY OF PEOTRY STUDENTS MTS NEGERI 1 EMPAT LAWANG}

\begin{abstract}
The research was conducted at MTs $N 1$ Empat Lawang. The problem in this study was whether there was an effect of the Outbound learning model on the ability to write poetry. The purpose of this study was to determine whether there was an effect of the Outbound learning method on the ability to write poetry. This study uses the Design Only Posttest Control method. The independent variable in this study is the Outbound learning model and the dependent variable is writing poetry. The population used in this study were 6 classes, the research sample of the VIII.6 class of the experimental class and the VIII.3 class of the control class. Collection using test techniques, data analysis techniques using the t test. Based on the criteria for testing the hypothesis that Ho is accepted if $t_{\text {count }}<t_{\text {table }}$ and $\mathrm{Ha}$ is accepted if $t_{\text {count }}>t_{\text {table }}$, therefore tcount with a value of 11.71 is greater than ttable with a value of 1.66 so that there is an effect of the Outbound method in writing poetry for students of class VIII MTS N 1 Empat Lawang.
\end{abstract}

Keywords: Outound Method. Writing Poetry 
Pengaruh Model Pembelajaran.... (Muhammad Syaifudin, Achmad Wahidy, Barkudin)

\section{A. PENDAHULUAN}

Pembelajaran adalah suatu sistem yang dirancang pada perangkat suatu komponen tertentu yang berkaitan antara satu sama lain untuk mencapai tujuan, disebuah sistem pembelajaran memiliki suatu komponen, antara lain tujuan, bahan, peserta didik, guru, metode, situasi, dan evaluasi (Ngalimun, 2018, p.12). Agar mencapai sebuah penentuan tujuan pembelajaran yaitu memerlukan adanya kebutuhan siswa mata ajaran, dan guru sendiri.

Dengan demikian memiliki tujuan pencapaian pembelajaran dan menyediakan tempat untuk peserta didik mendapatkan pengalaman-pengalaman belajar. Sebaiknya ketika mengasah keterampilan siswa hendaknya menggunakan bahasa Indonesia. Ketika menentukan tujuan pembelajaran peserta didik dapat menetukan tingkah laku siswa yang spesifik menuju tujuan tersebut. Guru harus dapat mengamati tingkah laku sepesifik yang dilakuka peserta didik. Misalnya membaca berita, menulis narasi, menulis puisi, agar dapat menjalankan tujuan pembelajaran terutama dalam pembelajaran bahasa Indonesia.

Mata pelajaran bahasa Indonesia merupakan pembelajaran yang harus diikuti oleh peserta didik. Ada empat keterampilan berbahasa yang semuanya memiliki keterkaitan yaitu, keterampilan menyimak, keterampilan berbicara, keterampilan membaca, keterampilan menulis. Keterampilan menulis merupakan kegiatan yang dilakukan peserta didik dalam mengungkapkan gagasan yang dimilikinya dalam lambang-lambang tulis, menulis itu memiliki tujuan yang hendak dicapai yang dikomunikasikan melalui bahasa tulis.

Alek (2011, p. 106) menyatakan Menulis adalah suatu kegiatan yang dilakukan untuk menciptakan sebuah catatan atau informasi pada suatu media yang dilakukan dengan menggunakan aksara. Menulis bisa dilakukan pada kertas dengan menggunakan alat-alat pena atau pensil. Kegiatan menulis berkembang pesat sejak diciptakanya teknik percetakanyang menyebabkan orang semakin giat menulis karna karya mereka mudah diterbitkan. (Wardarita, 2014, p.15) empat kemampuan berbahasa, yang paling membutuhkan penguasaan konsep yang paling tinggi adalah menulis. 
Dalam kurikulum sekolah menetapkan suatu aspek keterampilan menulis, dengan begitu menulis puisi juga termasuk dalam aspek kurikulum sekolah. puisi adalah kata-kata terbaik dalam susunan yang terbaik (Jabrohim, 2009, p.1). Puisi merupakan karya sastra memiliki keindahan yang disebabkan oleh diksi, majas, ritma dan rima. Puisi juga memiliki kekayaan makna yang terkandung disebabkan oleh segala unsur bahasa. Puisi menggunakan bahasa yang berbeda dengan bahasa yang digunakan sehari-hari.

Adapun kesulitan - kesulitan disaat dilaksanakanya pembelajaran menulis puisi yaitu adanya anggapan oleh peserta didik jika menulis puisi sangat sulit karena susah untuk menuangkan ide dan imajinasi hingga menjadi suatu kesulitan bagi para peserta didik. pembelajaran menulis puisi menjadi pembelajaran yang sangat tidak disukai oleh siswa oleh karena materi yang disampaikan kurang menarik minat siswa, agar dapat menarik minat siswa dibutuhkanya model pembelajaran yang menarik agar siswa dapat aktif dalam mempelajari pelajaran tersebut. Menentukan atau memilih model pembelajaran yang tepat dalam pembelajaran menulis puisi sangat diperlukan agar siswa dapat melakukan pembelajaran menulis puisi dengan baik dan siswa bisa mendapatkan hasil belajar yang maksimal.

Hal yang dapat dilakukan jika dilihat dari permasalahan tersebut ialah dengan menggunakan metode pembelajaran yang dapat merangsang minat siswa agar dapat belajar secara aktif dan bisa terlibat dalam pembelajaran menulis sehingga siswa bisa belajar secara mandiri dan tidak hanya menerima pembelajaran dari guru. Selanjutnya penggunaan strategi atau metode yang tepat dapat memperbaiki dan meningkatkan keterampilan mahasiswa dalam menulis (Armariena, 2018, p. 54). Suatu metode pembelajaran dan model bisa diterapkan oleh guru, banyak metode pembelajaran yang bisa diterapkan guru untuk mengajarkan siswa menulis puisi.

Salah satu model pembelajaran yang tepat yaitu model pembelajaran Outbound. Karena lingkungan sekolah yang mendukung dan memiliki ruang terbuka yang lebar, halaman sekolah yang luas, adanya taman-taman bunga. Sehingga penerapan metode Outbound di MTS Negeri 1 Empat Lawang sangat 
Pengaruh Model Pembelajaran.... (Muhammad Syaifudin, Achmad Wahidy, Barkudin)

tepat karena keadaan sekolahan yang sangat menunjang. Melalui model pembelajaran yang tepat, mahasiswa diharapkan mampu menulis puisi sesuai dengan ejaan yang baik dan benar (Armariena \& Murniviyanti, 2017). Adapun model pembelajaran yang akan dilakukan dalam penelitian ini adalah pembelajaran dengan menggunakan model pembelajaran Outbound. Model Outbound adalah pembelajaran yang dilakukan diluar ruangan sambil bermain (Shoimin, 2014, p.114).

\section{B. METODOLOGI PENELITIAN}

Penelitian ini merupakan penelitian dengan menggunakan metode eksperimen yang digunakan yaitu Posttes Only Control Design. Menurut Sugiyono (2013, p.109). Desain dalam penelitian ini ada dua kelompok masingmasing dipilih secara random (R), Kelompok pertama diberikan perlakuan (X) dan kelompok yang tidak. Kelompok yang diberikan perlakuan disebut kelompok eksperimen dan kelompok yang tidak diberikan perlakuan disebut kelompok Kontrol. Populasi peneliti ini adalah keseluruhan siswa MTS Negeri 1 Empat Lawang. Yang keseluruhanya berjumlah 211 yang terdiri dari kelas VIII.1 sampai kelas VIII.6.

Teknik yang digunakan dalam penelitian yaitu random sampling (sampel acak) yang berarti memilih secara acak satu kelas yang akan dijadikan sebagai kelas yang mengunakan model Outbound. Dari hasil mengundi didapatkan kelas VIII.6 sebagai kelas eksperimen dan kelas VIII.3 sebagai kelas kontrol (pembanding).

Teknik pengumpulan data yang digunakan dalam penelitian ini yaitu teknik tes, teknik tes dalam penelitian ini yaitu menulis puisi yang bertemakan mengenai keindahan alam dan lingkungan yang ada disekolah. Tes yang dilakukan dalam tes ini yakni dua kali tes yaitu kelas eksperimen adalah kelas yang diberikan perlakuan dan kelas kontrol adalah kelas yang tidak diberikan perlakuan.

Penelitian dilakukan di MTs N 1 Empat Lawang yang betempat di Desa Talang Banyu Kecamatan Tebing Tinggi Kabupaten Empat Lawang, MTS N 1 
Empat Lawang sangat menunjang dilakukanya penelitian ini dengan pembahasan menulis puisi menggunakan model pembelajaran Outbound. Dikarenakan fasilitas dan tempat sekolah yang mmenunjang. Seperti lebarnya ruangan terbuka disekolah ini kemudian juga banyak terdapat tanaman-tanaman bunga yang ada disekolahan, sekolahan juga berada didaerah perbukitan yang masih banyak ditumbuhi tanaman-tanaman hijau yang menjulang tinggi dan besar sehingga dapat menunjang penggunaann model pembelajaram Outbound. Penelitian ini dilaksanakan pada tanggal 12 agustus sampai 12 september 2020.

Hasil belajar siswa diperoleh dari hasil lembar menulis puisi siswa, kemudian danalisis untuk melihat kemampuan dan pemahaman siswa setelah diterapkan model pembelajaran Outbound. Nilai hasil tes belajar bahasa Indonesia siswa yang diperoleh dari kelas kontrol dan kelas eksperimen disusun dalam tabel distribusi frekuensi.

\section{HASIL PENELITIAN DAN PEMBAHASAN}

Untuk mengetahui hasil belajar siswa maka maka diberikan tes menulis puisi pada kelas ekperimen dan kelas kontrol. Dari tes inilah dapat diketahui hasil belajar siswa yang diajarkan dengan menggunakan model pembelajaran Outbound pada kelas eksperimen dan sebagai kelas pembanding yaitu kelas kontrol kelas yang tidak diberikan tindakan.

Penelitian ini telah dilaksanakan dikelas VIII.6 sebagai kelas eksperimen dan kelas VIII.3 sebagai kelas kontrol. Yang masing-masing kelas berjumlah 37 siswa. Dari hasil pemberian tes tersebut didapatkan nilai atau hasil belajar siswa dapat dilihat berdasarkan analisis data yang telah dilakukan dan diperoleh nilai sebagai berikut.

a. Hasil Nilai yang telah didapatkan dari Analisis Hasil Nilai Post-Test Menulis Puisi Siswa Kelas VIII.3 (Kontrol)

Hasil pemberian tes pada kelompok kontrol yang dilakukan di kelasVIII.3 MTS N 1 Empat Lawang. 
Pengaruh Model Pembelajaran.... (Muhammad Syaifudin, Achmad Wahidy, Barkudin)

Tabel 1 Hasil Nilai Post-Test Kelas Kontrol

\begin{tabular}{|c|c|c|c|c|c|c|}
\hline No & Interval & $\boldsymbol{f}_{\boldsymbol{i}}$ & $\boldsymbol{x}_{\boldsymbol{i}}$ & $\boldsymbol{x}_{\boldsymbol{i}}^{\mathbf{2}}$ & $\boldsymbol{f}_{\boldsymbol{i}} \boldsymbol{x}_{\boldsymbol{i}}$ & $\boldsymbol{f}_{\boldsymbol{i}} \boldsymbol{x}_{\boldsymbol{i}}^{\mathbf{2}}$ \\
\hline 1 & $50-54$ & 7 & 52 & 2704 & 364 & 132496 \\
\hline 2 & $55-59$ & 4 & 57 & 3249 & 228 & 51984 \\
\hline 3 & $60-64$ & 8 & 62 & 3844 & 496 & 246016 \\
\hline 4 & $65-70$ & 10 & 67 & 4489 & 670 & 448900 \\
\hline 5 & $71-75$ & 4 & 73 & 5329 & 292 & 85264 \\
\hline 5 & $76-80$ & 4 & 78 & 6084 & 312 & 97344 \\
\hline$\sum$ & & $\mathbf{3 7}$ & & & $\mathbf{2 3 6 2}$ & $\mathbf{1 0 6 2 0 0 4}$ \\
\hline
\end{tabular}

Berdasarkan tabel di atas bahwa siswa yang mendapatkan nilai 50 sebanyak 7 siswa atau 18,92\%, siswa yang mendapatkan nilai 55 sebanyak 4 siswa atau 10,81\%, siswa yang mendapatkan nilai 60 sebanyak 8 siswa atau $21,62 \%$, siswa yang mendapatkan nilai 65 sebnayak 7 siswa atau 18,92\%, siswa yang mendapatkan nilai 70 sebanyak 3 siswa atau $8,11 \%$, siswa yang mendapatkan nilai 75 sebanyak 4 siswa atau 10,81\%, dan siswa yang mendapatkan nilai 80 sebanyak 4 siswa atau $10,81 \%$.

Dilihat dari uraian di atas, diketahui bahwa terdapat 8 orang atau 21,62\% siswa kelas kontrol yang berhasil memenuhi keriteria ketuntasan minimal sekolah, yaitu 74 sehingga sesuai keriteria penilaian yang didapatkan kelas kontrol tidak memenuhi atau tidak tuntas karena jumlah siswa yang memenuhi nilai keriteria ketuntasan minimal 74 tidak mencapai $75 \%$ atau lebih.

b. Hasil Nilai yang telah didapatkan dari Analisis Hasil Nilai Post-Test Kelas VIII.6 Eksperimen.

Hasil pemberian tes pada kelompok eksperimen yang dilakukan di kelas VIII.6 MTS N 1 Empat Lawang.

Tabel 2 Hasil Nilai Post-Test Kelas Eksperimen

\begin{tabular}{|c|c|c|c|c|c|c|}
\hline No & Interval & $\boldsymbol{f}_{\boldsymbol{i}}$ & $\boldsymbol{x}_{\boldsymbol{i}}$ & $\boldsymbol{x}_{\boldsymbol{i}}^{\mathbf{2}}$ & $\boldsymbol{f}_{\boldsymbol{i}} \boldsymbol{x}_{\boldsymbol{i}}$ & $\boldsymbol{f}_{\boldsymbol{i}} \boldsymbol{x}_{\boldsymbol{i}}^{\mathbf{2}}$ \\
\hline 1 & $60-65$ & 3 & 63 & 3969 & 189 & 35721 \\
\hline
\end{tabular}


Wahana Didaktika Vol. 18 No.3 September 2020 : 338-346

\begin{tabular}{|c|c|c|c|c|c|c|}
\hline No & Interval & $\boldsymbol{f}_{\boldsymbol{i}}$ & $\boldsymbol{x}_{\boldsymbol{i}}$ & $\boldsymbol{x}_{\boldsymbol{i}}^{\mathbf{2}}$ & $\boldsymbol{f}_{\boldsymbol{i}} \boldsymbol{x}_{\boldsymbol{i}}$ & $\boldsymbol{f}_{\boldsymbol{i}} \boldsymbol{x}_{\boldsymbol{i}}^{\mathbf{2}}$ \\
\hline 2 & $66-71$ & 2 & 69 & 4761 & 138 & 19044 \\
\hline 3 & $72-71$ & 8 & 75 & 5625 & 600 & 360000 \\
\hline 4 & $78-83$ & 6 & 81 & 6561 & 486 & 236196 \\
\hline 5 & $84-89$ & 11 & 87 & 7569 & 957 & 915849 \\
\hline 6 & $90-95$ & 7 & 93 & 8649 & 651 & 423801 \\
\hline$\sum$ & & 37 & & & $\mathbf{3 0 2 1}$ & $\mathbf{1 9 9 0 6 1 1}$ \\
\hline
\end{tabular}

Berdasarkan tabel di atas bahwa siswa yang mendapatkan nilai 60 sebanyak 2 siswa atau 5,40\%, siswa yang mendapatkan nilai 65 sebanyak 1 siswa atau $2,70 \%$, siswa yang mendapatkan nilai 70 sebanyak 2 siswa atau 5,40\%, siswa yang mendapatkan nilai 75 sebnayak 8 siswa atau 21,62\%, siswa yang mendapatkan nilai 80 sebanyak 6 siswa atau 16,22\%, siswa yang mendapatkan nilai 85 sebanyak 11 siswa atau 29,73\%, siswa yang mendapatkan nilai 90 sebanyak 2 siswa atau 5,40\%, dan siswa yang mendapatkan nilai 95 sebanyak 5 siswa atau $13,51 \%$.

Dilihat dari uraian di atas, diketahui bahwa terdapat 32 orang atau $86,48 \%$ siswa kelas eksperimen yang berhasil memenuhi keriteria ketuntasan minimal sekolah, yaitu 74 sehingga sesuai keriteria penilaian yang didapatkan pembelajaran menulis puisi dengan menggunakan model pembelajaran Outbound terhadap kemampuan menulis puisi kelas VIII MTS N 1 Empat Lawang, pembelajaran yang dilakukan di kelas VIII.6 kelompok eksperimen dinyatakan berhasil atau tuntas karena siswa yang mencapai nila kriteria ketuntasan minimum 74 yang telah ditentukan oleh sekolah mencapai $75 \%$ atau lebih.

Dalam penelitian ini peneliti bertujuan untuk mengetahui bagaimanakah pengaruh metode pembelajaran Outbound terhadap kemampuan menulis puisi siswa kelas VIII MTs N 1 Empat Lawang. Dalam penelitian ini peneliti mengunakan model pembelajaran Outbound yang berikan untuk kelas VIII.6 yaitu kelompok eksperimen, dan sedangkan kelas VIII.3 yaitu adalah kelompok kontrol 
yang tidak mengunakan metode pembelajaran Outbound hanya menggunakan metode konvensional, ceramah, tanya jawab, dan penugasan.

Saat peneliti menerapkan metode Outbound kepada kelompok eksperimen siswa lebih aktif dalam berkelompok siswa juga lebih bersemangat saat menulis puisinya. Sedangkan kelompok yang tidak menggunakan metode pembelajaran Outbound kebanyakan siswa hanya diam dan ada yang mengantuk ataupun mengobrol dengan kawannya. Jumlah siswa dalam penelitian ini yaitu yang kelas eksperimen 37 orang dam kelas kontrol 37 orang. Tes yang digunakan dalam penelitian ini adalah menulis puisi mengenai lingkungan sekolah. Tujuanya ingin menjak siswa untuk lebing mengenal lingkungan sekolahnya yang memiliki pemandangan alam yang indah yang dapat dijadikan sebuah puisi.

Hasil deskripsi data penelitian didapatkan nilai rata-rata kelompok eksperimen yaitu 83,1 dan kemudian kelas kontrol didapatkan hasil nilai rata-rata menulis puisi yaitu 63,5 Dilihat dari hasil tersebut dapat diperoleh bahwa hasil kelompok eksperimen lebih tinggi dibandingkan dengan hasil kelompok kontrol.

Berdasarkan hasil distribusi tengan $\mathrm{dk}=(\mathrm{n} 1+\mathrm{n} 2-2)=(37+37-2)=72$ oleh karena itu pada penelitian didapat thitung $=11,71$ dan ttabel $=1,66$ hal ini menunjukkan bahawa thitung > ttabel atau 11.48>1,66 dengan demikian maka dapat dikatakan Ho ditolak dan Ha diterima yang artinya model pembelajaran Outbound terhadap kemampuan menulis puisi terdapat pengaruh yang positif.

Dalam penelitian pembelajaran dengan menggunakan model Outboundterhadap kemampuan menulis puisi siswa kelas VIII MTs N 1 Empat Lawang bisa mempengaruhi hasil belajar siswa. Oleh sebab itu model pembelajaran Outbound dapat digunakan sebagai metode untuk pembelajaran bahasa Indonesia.

\section{SIMPULAN}

Setelah dilihat dari hasil deskripsi data, mengenai analisis data dan pembahasan pada bab IV, bisa diambil kesimpulan yakni sebagai berikut. Hasil rata-rata dari kelas VIII.6 yaitu kelompok eksperimen kelompok yang diberikan pelakuan menggunakan metode pembelajaran Outbound mendapatkan nilai rata- 
rata sebesar 83,1 sedangkan kelas VIII.3 yaitu kelompok kontrol kelompok yang tidak diberikan mendapatkan nilai rata-rata 63,5, berdasarkan fakta tersebut maka dapat disimpulkan bahwa kelas VIII.6 atau kelompok eksperimen lebih tinggi jika dibandingkan dengan kelas VIII.3 yaitu kelompok kontrol.

Setelah dihitung pengujian hipotesisnya maka mendapatkan angka bahwa pengujian hipotesis Ho diterima jika thitung $<$ ttabel dan Ha diterima jika thitung $\geq$ ttabel. Oleh karena itu thitung dengan nilai 11.71 lebih besar dibandingkan ttabel dengan nilai 1.66 sehingga ada pengaruh pada metode pembelajaran Outbound dalam menulis puisi siswa kelas VIII MTS N 1 Empat Lawang.

\section{DAFTAR PUSTAKA}

Alek, A. (2011). Bahasa Indonesia untuk Perguruan Tinggi. Jakarta: Fajar Interpratama Offset.

Armariena, D. N., \& Murniviyanti, L. (2017). Penulisan Cerpen Berbasis Kearifan Lokal Sumatera Selatan dengan Metode Image Streaming dalam Proses Kreatif Mahasiswa. Jurnal PEMBAHSI (Pembelajaran Bahasa dan Sastra Indonesia), 7(1), 88-115.

Armariena, D. N. (2018). Penulisan Puisi Bertema Lokal Budaya dengan Model Sugesti Mahasiswa. Parataksis: Jurnal Bahasa Sastra dan Pembelajaran Bahasa Indonesia, 1, 53-61.

Jabrohim, S. A. (2009). Cara Menulis Kreatif. Yogyakarta: Pustaka Pelajar.

Ngalimun. (2018). Strategi dan Model Pembelajaran. Yogyakarta: Aswaja Pressindo

Shoimin, A. (2017). 68 Model Pembelajaran Inovatif dalam Kurikulum 2013. Yogyakarta: Ar-Ruzz Media.

Sugiyono. (2019). Metode Penelitian Kuantitatif Kualitatif dan R\&D. Bandung: Alfabeta.

Wardarita, R. (2015). Kajian Bahasa dan Sastra Indonesia. Yogyakarta: Elmatera. 